\title{
Ultra-Low-Voltage Low-Power Bulk-Driven Quasi-Floating-Gate Operational Transconductance Amplifier
}

\author{
Ziad Alsibai and Salma Bay Abo Dabbous \\ Department of Microelectronics, Brno University of Technology, 61600 Brno, Czech Republic \\ Correspondence should be addressed to Ziad Alsibai; xalsib00@stud.feec.vutbr.cz
}

Received 27 May 2014; Accepted 8 August 2014; Published 27 August 2014

Academic Editor: Bo K. Choi

Copyright (C) 2014 Z. Alsibai and S. Bay Abo Dabbous. This is an open access article distributed under the Creative Commons Attribution License, which permits unrestricted use, distribution, and reproduction in any medium, provided the original work is properly cited.

\begin{abstract}
A new ultra-low-voltage (LV) low-power (LP) bulk-driven quasi-floating-gate (BD-QFG) operational transconductance amplifier (OTA) is presented in this paper. The proposed circuit is designed using $0.18 \mu \mathrm{m}$ CMOS technology. A supply voltage of $\pm 0.3 \mathrm{~V}$ and a quiescent bias current of $5 \mu \mathrm{A}$ are used. The PSpice simulation result shows that the power consumption of the proposed BD-QFG OTA is $13.4 \mu \mathrm{W}$. Thus, the circuit is suitable for low-power applications. In order to confirm that the proposed BD-QFG OTA can be used in analog signal processing, a BD-QFG OTA-based diodeless precision rectifier is designed as an example application. This rectifier employs only two BD-QFG OTAs and consumes only $26.8 \mu \mathrm{W}$.
\end{abstract}

\section{Introduction}

In the late sixties, the Radio Corporation of America (RCA) and then General Electric (GE) came out with the operational transconductance amplifier, hereafter called OTA. The name means essentially a controllable resistance amplifier. OTA is a key functional block used in many analog and mixedmode circuits. It is a special case of an ideal active element, and its implementation in IC form makes it indispensable today in discrete and fully integrated analog network design. The ideal OTA as shown in Figure 1 can be considered as a differential voltage-controlled current source (DVCCS); its transconductance " $g_{m}$ " represents the ratio of the output current to the differential input voltage, that is, $I_{\text {out }} /\left(V_{1}-V_{2}\right)$. This transconductance is used as a design parameter and it is usually adjustable by the amplifier bias current $\left(I_{\text {bias }}\right)$. The benefit of this adjusting possibility is acquiring the ability of electronic orthogonal tunability to circuit parameters. It could be noted that tunability has a main role in integrated circuits, especially to satisfy a variety of design specifications. Thus, OTA has been implemented widely in CMOS and bipolar and also in BiCMOS and GaAs technologies [1].

The OTA is similar to the standard operation amplifier (OPA) in the sense of infinite input impedances, but its output impedance is much higher and that makes OTA more desirable than any ordinary amplifier. Recently, the multipleoutput-OTA (MO-OTA) has been introduced and used, on par with the ordinary operation amplifier, as a basic block in many applications, particularly for realizing universal filters which are able to implement several second-order transfer functions with a minimum of adjustments. The literature provides numerous examples of OTA-based biquad structures, as well as active elements such as current conveyor (CC), current differencing transconductance amplifier (CDTA), currentthrough transconductance amplifier (CTTA), and currentconveyor transconductance amplifier (CCTA).

The symbol and the equivalent circuit of ideal OTA are shown in Figures 1(a) and 1(b), respectively [1]. Simple applications of the OTA include voltage amplification, voltagevariable resistor (VVR), voltage summation, integration, gyrator realization, practical OTAs, current conveyor, and active RC filters. In addition, one of OTA's principal uses is in implementing electronically controlled applications such as variable frequency oscillators and variable gain amplifier stages which are more difficult to implement with standard OPAs.

Recently, Low power analog circuit design is undergoing a very considerable boom. However, circuit designers encounter difficulties to preserve reliable performance of the analog circuits with scaling down their supply voltage, 


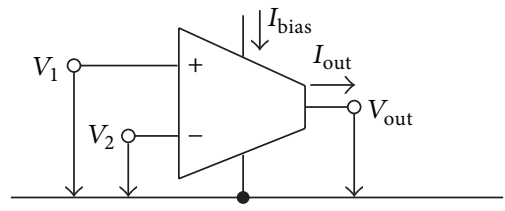

(a)

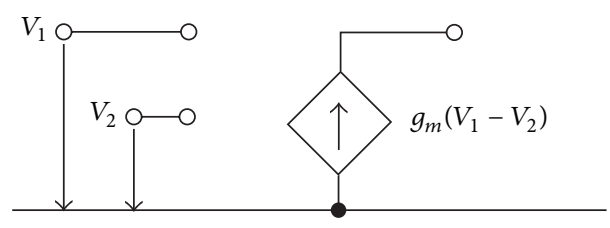

(b)

FIGURE 1: Ideal operational transconductance amplifier, (a) symbol and (b) equivalent circuit.

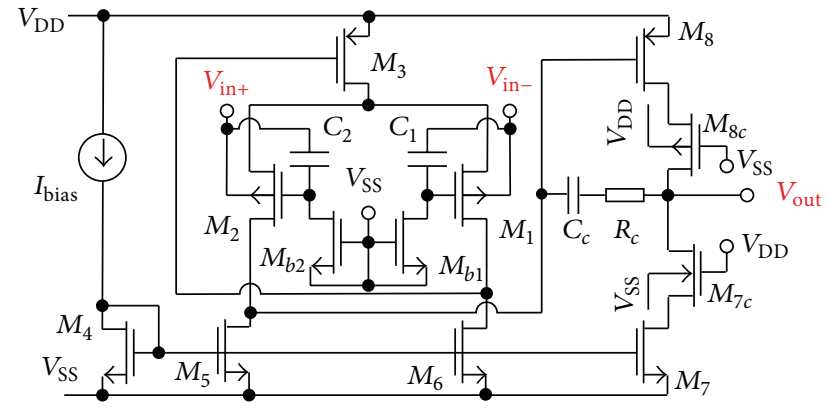

FIGURE 2: The internal structure of BD-QFG OTA.

owing to the fact that the threshold voltage and supply voltage are not decreased proportionally. Hence, various techniques based on CMOS technology have emerged to overcome the rather high threshold voltage problem of MOS transistors, such as unconventional MOS techniques, that is, floating-gate (FG), quasi-floating-gate (QFG), bulk-driven $(\mathrm{BD})$, bulk-driven floating-gate (BD-FG), and bulk-driven quasi-floating-gate (BD-QFG) MOS transistor $[2,3]$. Utilizing these techniques offers circuit simplicity, high functionality, extended input voltage range, and ultra-LV LP operation capability. Thus, they are very suitable for ultra-LV LP applications as battery-powered implantable and wearable medical devices.

In this paper, The $\mathrm{BD}-\mathrm{QFG}$ technique has been chosen to be utilized to build LP LV OTA, since it enjoys higher transconductance value, higher bandwidth, and smaller input referred noise in comparison with other unconventional techniques. To verify the functionality of the proposed OTA voltage mode diodeless precision rectifier is introduced in this work.

The organization of this paper is as follows: in Section 2 the CMOS internal structure of the BD-QFG OTA is described. In Section 3 the principle of BD-QFG OTA-based diodeless precision rectifier is presented. The simulation results are provided in Section 4; eventually, Section 5 is the conclusions.

\section{Bulk-Driven Quasi-Floating-Gate Operational Transconductance Amplifier (BD-QFG OTA)}

The circuit, which is shown in Figure 2, consisted of two stages. The first stage consists of BD-QFG differential input $M_{1}$ and $M_{2}$. The gates of these transistors are tied to the negative supply voltage $V_{\mathrm{SS}}$ through extremely high value resistors constructed by transistors $M_{b 1}$ and $M_{b 2}$ which are operating in cutoff region. The input terminals are connected to $M_{1}$ and $M_{2}$ from two sides: capacitively coupled to the quasi-floating-gates via $C_{1}$ and $C_{2}$ from one side and connected to bulk terminals from the other side.

Transistors $M_{4}, M_{5}, M_{6}$, and $M_{7}$ act as a multiple output current mirror applying the constant current source $I_{\text {bias }}$ to each branch of the circuit. Transistors $M_{5}$ and $M_{6}$ form the active load and transistor $M_{3}$ acts as tail current source for the differential input stage. The input voltage terminals are connected to the bulk terminals of $M_{1}$ and $M_{2}$; therefore, high input impedance is achieved.

The use of bulk-driven quasi-floating-gate flipped voltage follower for the differential input stage makes the minimum power supply voltage $V_{\mathrm{DD}(\min )}$. The supply voltage is given by [4]

$$
V_{\mathrm{DD}(\min )}=V_{\mathrm{GS}\left(M_{3}\right)}+V_{\mathrm{DS}\left(M_{6}\right)} .
$$

Equation (1) shows the capability of the proposed BDQFG OTA structure for operation under lower supply voltage.

The second stage consists of $M_{7}, M_{7 c}$ and $M_{8}, M_{8 c}$. Cascode structure is used to implement the gain stage in order to provide significantly high-value output impedance, consequently to achieve high voltage gain. Output impedance can be calculated from the following equation:

$$
\begin{aligned}
r_{o}=1 & \\
\times & \left(\left(\left(g_{o, M 7} g_{o, M 7 c}\right) /\left(g_{m, M 7 c}+g_{m b, M 7 c}\right)\right)\right. \\
& \left.+\left(\left(g_{o, M 8} g_{o, M 8 c}\right) /\left(g_{m, M 8 c}+g_{m b, M 8 c}\right)\right)\right)^{-1} .
\end{aligned}
$$

\section{BD-QFG OTA-Based Diodeless Precision Rectifier}

A precision rectifier is one of important nonlinear circuits, which is extensively used in analog signal processing systems. In precision rectification, a bidirectional signal is converted to one-directional signal. Typically, a conventional rectifier could be realized by using diodes for its rectification, but diode cannot rectify signals whose amplitudes are less than the threshold voltage (approximately $0.7 \mathrm{~V}$ for silicon diode and approximately $0.3 \mathrm{~V}$ for germanium diode). As a result, diode-only rectifiers are used in only those applications in which the precision in the range of threshold voltage is insignificant, such as RF demodulators and DC voltage supply 


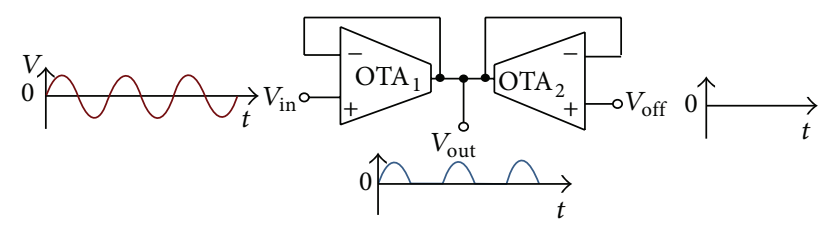

FIGURE 3: BD-QFG half-wave rectifier.

rectifiers, but for applications requiring accuracy in the range of threshold voltage the diode-only rectifier cannot be used. This can be overcome by using integrated circuit rectifiers instead.

Traditional methods of realizing precision rectifier circuits include the use of operational amplifiers, resistors, and either diodes [5-9] or alternating source-followers [10]. A number of current conveyors-based current-mode rectifier circuits were introduced in the literature [7, 11-16]. The rectifier circuits in [11-13] employ diodes and resistors in addition to second generation current conveyors (CCIIs). The circuit proposed in [7] employs bipolar current mirrors in addition to a CCII and a number of resistors. The rectifier circuit in [14] employs four current controlled conveyors (CCCIIs) and resistors. However, the use of resistor makes these circuits not ideal for integration. Therefore, precision rectifiers by using all-MOS transistors are proposed [17-26]. Authors in [27] proposed a circuit which employs two CCIIs and two MOS transistors. Authors in [28] presented a circuit which employs an amplifier and a simple voltage comparator. Author in [27] introduced a rectifier which employs two differential difference current conveyors (DDCCs). A new technique for realizing a precision half-wave voltage rectifier in CMOS technology is proposed; this technique is based on bulk-driven quasi-floating-gate operational transconductance amplifier (BD-QFG OTA).

Diodeless half wave rectifier based on bulk-driven quasifloating-gate OTA is shown in Figure 3. This circuit is a WTAlike (winner-take-all) circuit. The principle of work is as follows: if we applied a voltage signal to $V_{\text {in }}$ terminal and a zero to $V_{\text {off }}$ terminal, the output voltage would equal the maximum voltage of both inputs. In other words, positive half of the signal wave is passed, while the other half is blocked. For an input voltage $V_{\text {in }}$ the ideal half-wave rectified output $V_{\text {out }}$ is given by

$$
V_{\text {out }}= \begin{cases}V_{\text {in }} & \text { if } V_{\text {in }}>0 \\ 0 & \text { otherwise }\end{cases}
$$

It is worth mentioning that the same configuration shown in Figure 3 could be used as full-wave rectifier just by applying $V_{\text {in }}$ (an identical signal of $V_{\text {in }}$ shifted $180^{\circ}$ ) to $V_{\text {off }}$ terminal.

\section{Simulation Results}

The proposed BD-QFG OTA was designed and simulated using TSMC $0.18 \mu \mathrm{m} \mathrm{N}$-well CMOS. The used PSpice model is available on [29]. The supply voltage was $\pm 0.3 \mathrm{~V}$, the biasing current was $I_{\text {bias }}=5 \mu \mathrm{A}$. and the power consumption was 13.4 $\mu \mathrm{W}$. The optimal transistor aspect ratios and the values

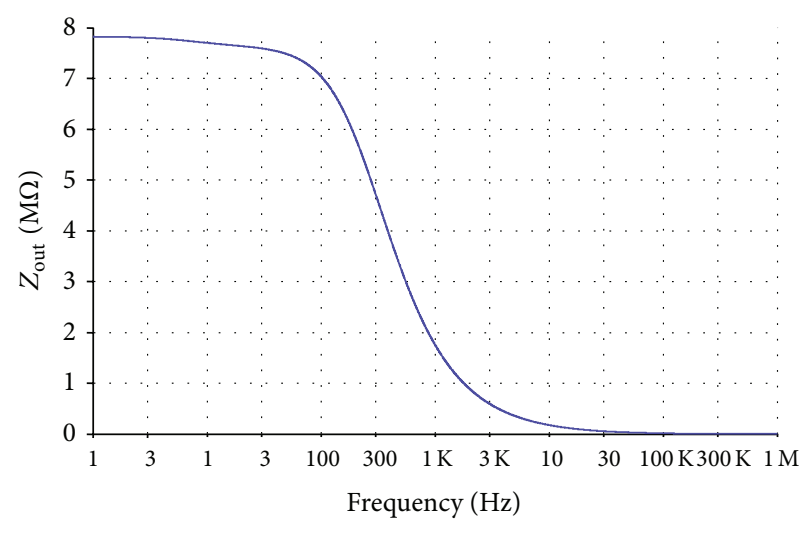

FIGURE 4: Output impedance versus frequency.

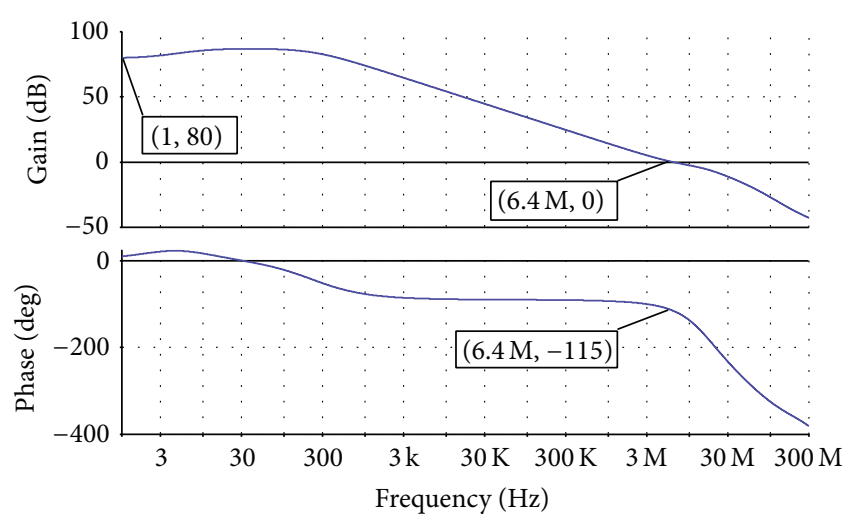

FIGURE 5: Frequency response of BD-QFG OTA.

TABLE 1: Transistors aspect ratios for Figure 2.

\begin{tabular}{lc}
\hline BD-QFG OTA & $W / L[\mu \mathrm{m} / \mu \mathrm{m}]$ \\
\hline$M_{1}, M_{2}$ & $20 / 0.3$ \\
$M_{b 1}, M_{b 2}$ & $30 / 2$ \\
$M_{3}, M_{8}$ & $100 / 0.3$ \\
$M_{4}, M_{5}, M_{6}$ & $4 / 0.3$ \\
$M_{7}$ & $8 / 0.3$ \\
$M_{7 c}$ & $45 / 2$ \\
$M_{8 c}$ & $100 / 2$ \\
& \\
& \\
\hline & $C_{1}=C_{2}=0.4 \mathrm{pF}$ \\
\hline
\end{tabular}

of components are given in Table 1. Table 2 shows a list of measured operational amplifier benchmarks used to evaluate proposed OTA. Features of the circuit (shown in Figure 2) are listed in the first column, along with values of other works listed in other columns.

Figure 4 shows the simulated magnitude of output impedance of OTA. $Z_{\text {out }}$ is high as expected; its value is $7.83 \mathrm{M} \Omega$. The AC gain and phase responses of the BD-QFG OTA with $3 \mathrm{pF}$ load capacitance are shown in Figure 5. The open-loop gain is $80 \mathrm{~dB}$ and the gain-bandwidth product is $6.4 \mathrm{MHz}$. The phase margin is $65^{\circ}$ which guarantees the circuit stability. The voltage follower frequency response of the proposed 
TABLE 2: BD-QFG OTA performance benchmark indicators.

\begin{tabular}{|c|c|c|c|c|c|}
\hline Parameters & This work & Koziel and Szczepanski [33] & Majumdar [34] & Li and Raut [35] & Zhang et al. [36] \\
\hline \multicolumn{6}{|l|}{ CMOS technology } \\
\hline$[\mu \mathrm{m}]$ & 0.18 & 0.5 & 0.35 & 0.35 & 0.18 \\
\hline \multicolumn{6}{|l|}{ Power supply } \\
\hline$[\mathrm{V}]$ & \pm 0.3 & \pm 2.5 & 3.3 & 3.3 & 1.8 \\
\hline \multicolumn{6}{|l|}{ Power consumption } \\
\hline$[\mu \mathrm{W}]$ & 13.4 & 6800 & 3370 & 2330 & 590 \\
\hline \multicolumn{6}{|l|}{ Transistors number } \\
\hline$[/]$ & 12 & 37 & 14 & 22 & 68 \\
\hline \multicolumn{6}{|l|}{ AC gain } \\
\hline$[\mathrm{dB}]$ & 51 & 65 & 80.4 & 65 & 55 \\
\hline \multicolumn{6}{|l|}{ Linearity range } \\
\hline$[\mathrm{mV}]$ & \pm 0.3 & \pm 0.75 & \pm 0.1 & l & \pm 0.27 \\
\hline \multicolumn{6}{|l|}{ Output resistance } \\
\hline$[\mathrm{M} \Omega]$ & 0.317 & 3.4 & l & 1.2 & 8.3 \\
\hline \multicolumn{6}{|l|}{$-3 \mathrm{~dB}$ bandwidth } \\
\hline$[\mathrm{MHz}]$ & 59 & 100 & 123.2 & 100 & 200 \\
\hline
\end{tabular}

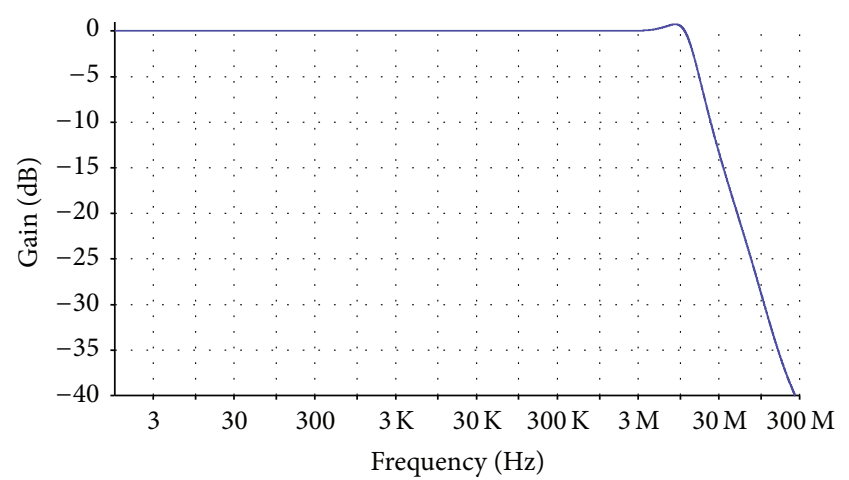

FIGURE 6: Frequency response of BD-QFG OTA as a voltage follower.

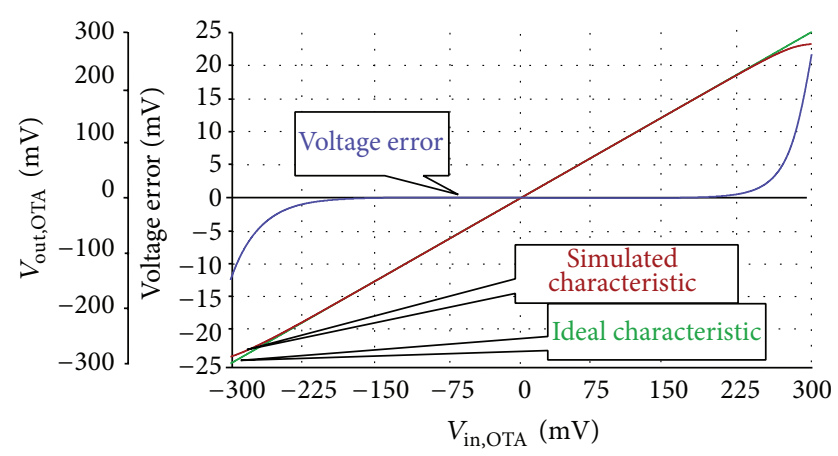

FIGURE 7: DC transfer characteristic and voltage error of the BDQFG OTA.

circuit is shown in Figure 6. The cutoff frequency is about $15 \mathrm{MHz}$.

Figure 7 presents the DC transfer characteristic of the BD-QFG OTA. For input voltage range from -266 to $266 \mathrm{mV}$ the voltage error is below $4 \mathrm{mV}$. Therefore, using $V_{\text {off }}=0 \mathrm{~V}$ and maximum input amplitude $V_{m \cdot \max }$ of $\pm 250 \mathrm{mV}$, the OTA is not expected to have strong impact on the overall rectifier accuracy.

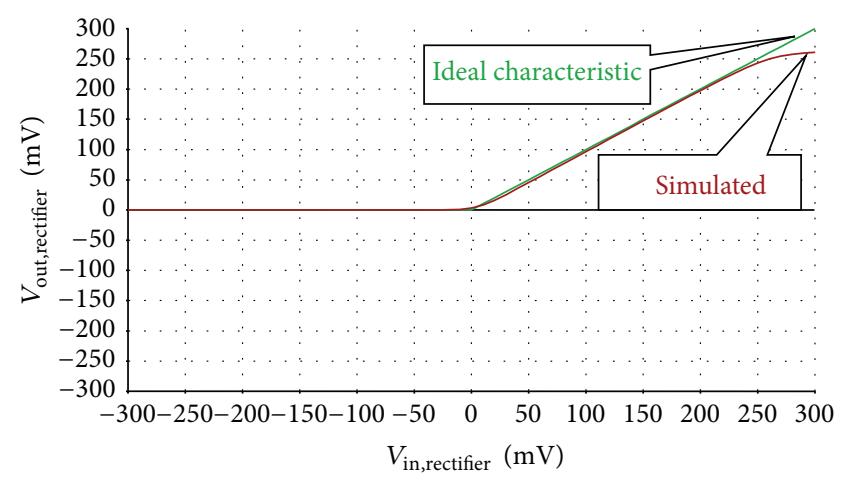

FIGURE 8: DC transfer characteristic of BD-QFG half-wave rectifier.

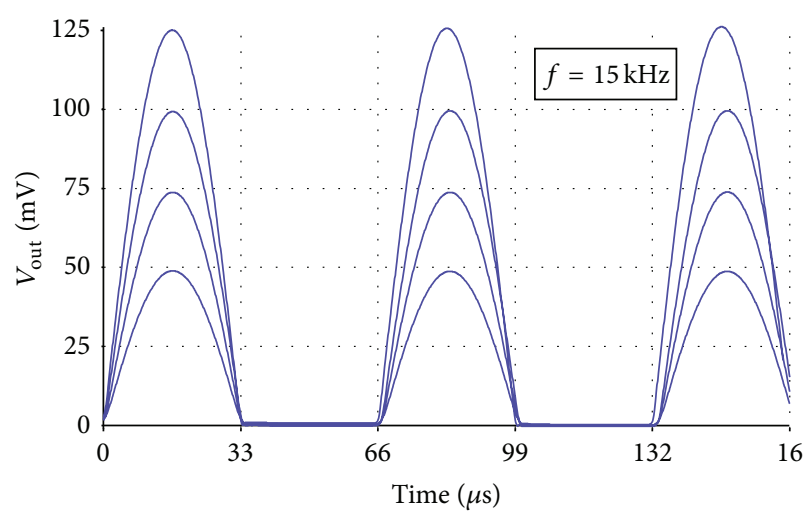

FIGURE 9: Transient analyses of output waveforms with $15 \mathrm{kHz}$ and various amplitudes of the input signal.

The diodeless half-wave precision rectifier shown in Figure 3 was simulated using BD-QFG OTA shown in Figure 2. The supply voltage of $\pm 0.3 \mathrm{~V}$ and the bias current of $I_{\text {bias }}=5 \mu \mathrm{A}$ for OTAs were used. The circuit consumes $26.8 \mu \mathrm{W}$. Figure 8 shows the DC transfer characteristic of BDQFG half-wave rectifier in comparison with the ideal one and it confirms the precise rectification for input amplitude ranging $\pm 250 \mathrm{mV}$. Figure 9 shows the transient response of 


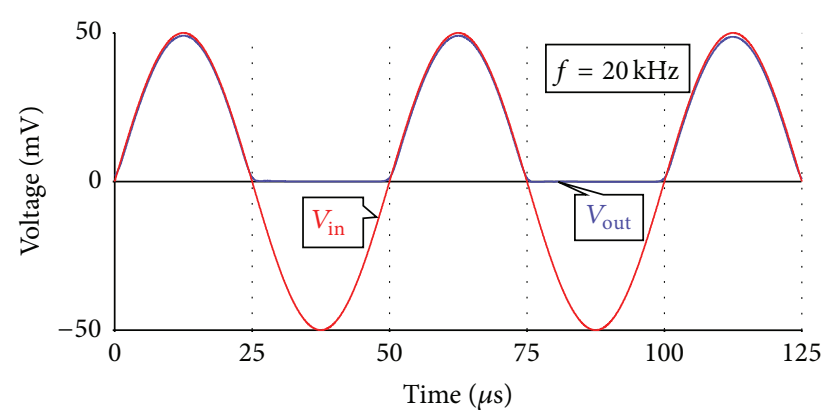

(a)

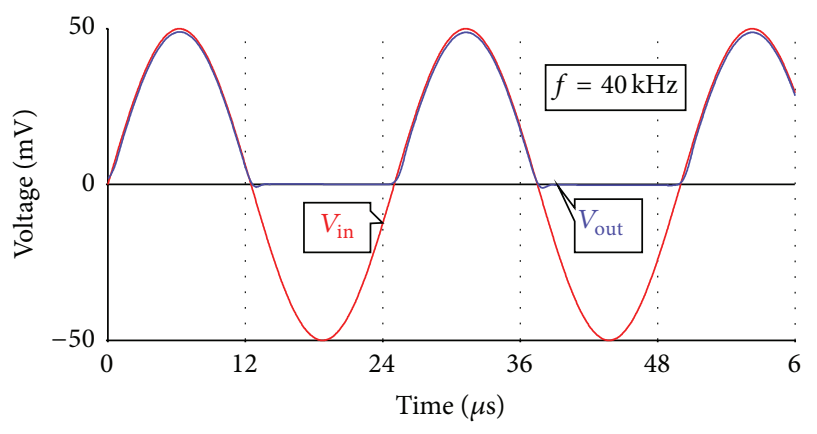

(c)

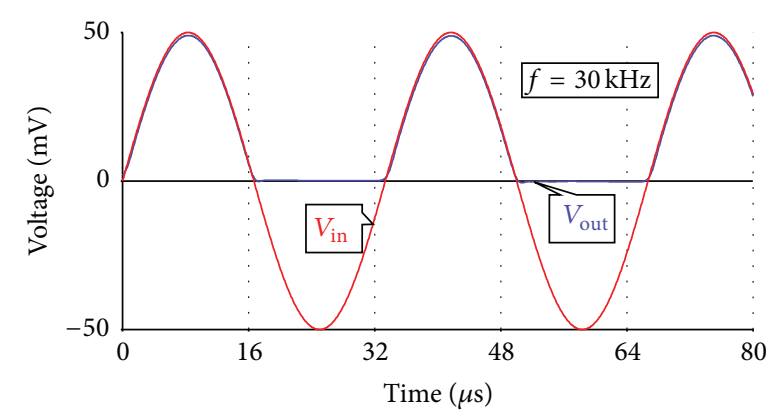

(b)

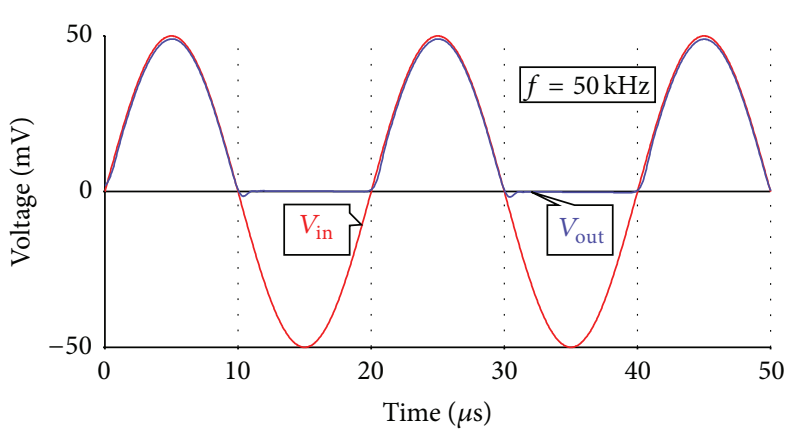

(d)

FIgURE 10: Transient analyses of input and output waveforms with $V_{m}=50 \mathrm{mV}$ and (a) 20, (b) 30, (c) 40, and (d) $50 \mathrm{kHz}$.

the output waveforms for input signal of $15 \mathrm{kHz}$ and amplitudes from $50 \mathrm{mV}$ to $125 \mathrm{mV}$ with step of $25 \mathrm{mV}$. Hence, the rectifier is capable of rectifying a wide range of amplitudes. Figure 10 shows the transient responses of the input and output waveforms with amplitude of $100 \mathrm{mV}$ and frequency of $20 \mathrm{kHz}, 30 \mathrm{kHz}, 40 \mathrm{kHz}$, and $50 \mathrm{kHz}$. The load capacitor $C_{\text {load }}$ for simulations done in Figures 9 and 10 was set to $5 \mathrm{pF}$.

To demonstrate the temperature performance of proposed circuit, the proposed circuit was simulated at the frequency of $10 \mathrm{kHz}$ by changing temperature. Figure 11 shows the output waveforms of the proposed rectifier at temperatures of $0^{\circ} \mathrm{C}, 27^{\circ} \mathrm{C}$, and $100^{\circ} \mathrm{C}$. From Figure 11, it can be seen that the proposed circuit provides excellent temperature stability without any compensation technique.

To evaluate the quality of the rectification process as a function of the amplitude and the frequency of the input signal, two types of characteristics are proposed [29]. The first type is $P_{\mathrm{AVR}}$ (AVR: average value ratio) which is the ratio of the average value of the rectified output signal $v_{\text {out }}$ and the average value of the sinusoidal input signal after its ideal halfwave rectification:

$$
P_{\mathrm{AVR}}=\frac{(1 / T) \int_{0}^{T / 2} v_{\text {(out) }} d t}{(1 / \pi) V_{m}},
$$

where $T$ and $V_{m}$ are the period and amplitude of the sinusoidal input signal, respectively. The ideal operation of the rectifier is then characterized by the value $P_{\mathrm{AVR}}=1$. With increasing the frequency and decreasing the amplitude of the input signal, the deviation from the ideal operation is indicated by a change, mostly a decrease in $P_{\mathrm{AVR}}$ below one.

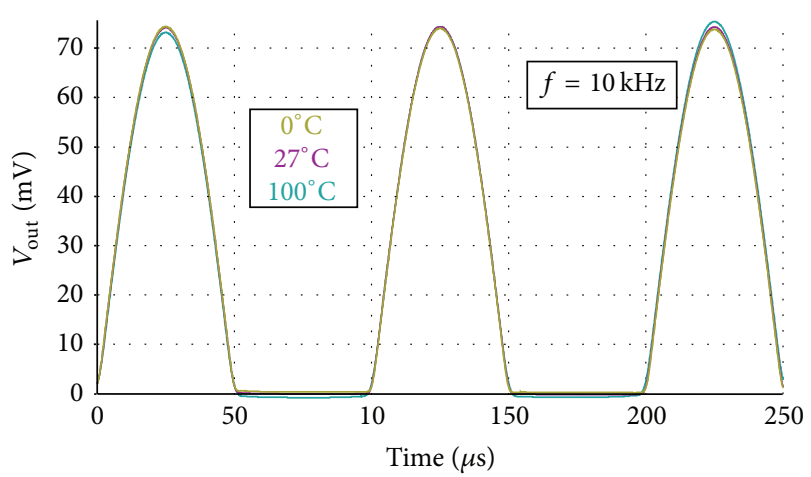

FIGURE 11: Outputs waveforms at different temperatures.

The second type of characteristic is defined more rigorously as a ratio of two root mean square "RMS" values, the RMS of the difference of the real and ideal output signals, $v_{\text {out }}$ and $v_{\text {ideal }}$, and the RMS value of the ideal signal:

$$
P_{\mathrm{RMSE}}=\frac{\sqrt{(1 / T) \int_{0}^{T / 2}\left[v_{\text {out }}(t)-v_{\text {ideal }}(t)\right]^{2} d t}}{(1 / 2) V_{m}} .
$$

Here, the suffix RMSE is an abbreviation of the term "root mean square error." For ideal circuit operation, that is, $v_{\text {out }}(t)=v_{\text {ideal }}(t)$, the result is $P_{\text {RMSE }}=0$, while in the case of total attenuation of the output signal $P_{\mathrm{RMSE}}=1$. For extra high distortions, when the mutual energy of signals $v_{\text {out }}$ and $v_{\text {ideal }}$ can be negative, one can obtain $P_{\mathrm{RMSE}}>1$. Figure 12 shows the $P_{\mathrm{AVR}}$ (a) and $P_{\mathrm{RMSE}}$ (b) versus frequency in range of 


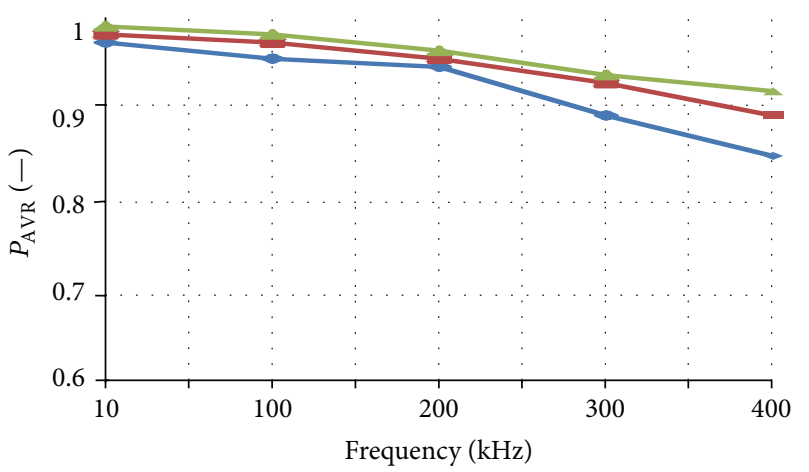

$50 \mathrm{mV}$

$100 \mathrm{mV}$

$150 \mathrm{mV}$

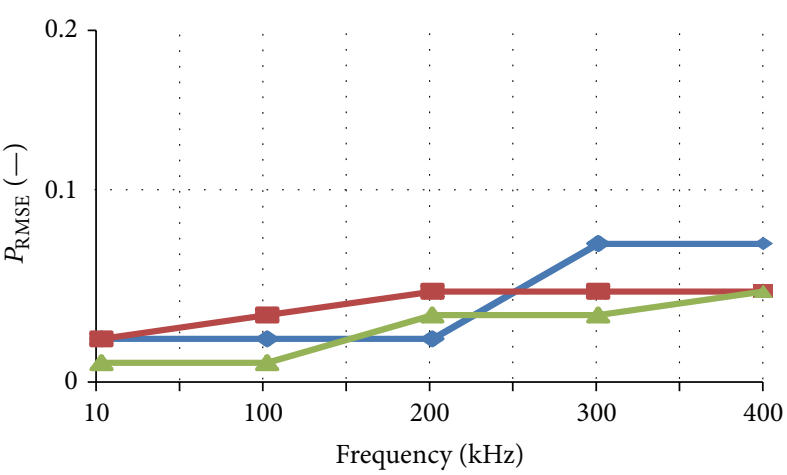

$50 \mathrm{mV}$

$100 \mathrm{mV}$

$150 \mathrm{mV}$

(a)

(b)

Figure 12: AVR (a) and RMSE (b) versus frequency for three amplitudes of the input voltage (50, 100, and 150) mV.

TABLE 3: A comparison with other reported implementations in the literature.

\begin{tabular}{lcccc}
\hline Parameter & Proposed rectifier & {$[30]$} & {$[31]$} & {$[32]$} \\
\hline $\begin{array}{l}\text { Technology used } \\
{[\mu \mathrm{m}]}\end{array}$ & 0.18 & 1.5 & 0.18 & 0.35 \\
$\begin{array}{l}\text { Supply voltage } \\
\quad[\mathrm{V}]\end{array}$ & \pm 0.3 & 2.8 & 1.8 & 1 \\
$\begin{array}{l}\text { Power consumption } \\
\quad[\mu \mathrm{W}]\end{array}$ & 13.4 & 2.8 & 1.08 & 0.06 \\
$\begin{array}{l}\text { Maximum amplitude } \\
{[\mathrm{mV}]}\end{array}$ & $225^{*}$ & 850 & 630 & 230 \\
$\begin{array}{l}\text { Maximum frequency } \\
{[\mathrm{kHz}]}\end{array}$ & $400^{*}$ & 10 & 20 & 0.1 \\
$\begin{array}{l}\text { FOM } \\
\quad \%\end{array}$ & 37.5 & 30 & 35 & 23 \\
\hline
\end{tabular}

${ }^{*} 0.85 \leq P_{\text {AVR }} \leq 1,0<P_{\text {RMSE }}<0.1$.

${ }^{* *} \mathrm{FOM}=($ maximum amplitude/supply voltage $) * 100$.

$10 \mathrm{kHz}$ up to $500 \mathrm{kHz}$ for three amplitudes of the input voltage $(50,100$, and 150$) \mathrm{mV}$. As one can notice from the figure, over the full range of frequency, the value of $P_{\mathrm{AVR}}$ ranges from 1 to 0.85 and the value of $P_{\mathrm{RMSE}}$ is below 0.1. The values of $P_{\mathrm{AVR}}$ and $P_{\mathrm{RMSE}}$ achieved confirm the quality of the rectification process of the proposed rectifier.

Table 3 provides comparison of the proposed rectifier with three half wave rectifiers introduced in [30-32]. To compare their performance figure of merit FOM is provided, which indicates the efficiency of the design regarding the maximum allowable input swing over voltage supply. Higher value of the FOM translates proportionate advantage in terms of input voltage range. It is notable that the proposed rectifier possesses the highest value of FOM. Besides, the proposed rectifier offers the highest maximum frequency with ultra-LV operation capability and simple CMOS internal structure.

\section{Conclusions}

In this paper, a new ultra-low-voltage supply and lowpower consumption BD-QFG OTA is presented. The active building block was simulated using TSMC $0.18 \mu \mathrm{m} \mathrm{N}$-well CMOS technology. It is demonstrated that the proposed BD-QFG OTA can operate at $\pm 0.3 \mathrm{~V}$ supply voltage and consumes $13.4 \mu \mathrm{W}$ of static power. The proposed BD-QFG OTA is used to realize diodeless precision rectifier as an example application. Proposed BD-QFG OTA could be used in LV and LP applications such as bioelectronics, biosensors, and biomedical systems. The simulation results confirm the workability of the active building block.

\section{Conflict of Interests}

The authors declare that there is no conflict of interests regarding the publication of this paper.

\section{Acknowledgments}

The described research was performed in laboratories supported by the SIX project, registration no. CZ. 1.05/2.1.00/ 03.0072, the operational program Research and Development for Innovation, and has been supported by Czech Science Foundation Project no. P102-14-07724S.

\section{References}

[1] T. Deliyannis, Y. Sun, and J. K. Fidler, ContinuousTime Active Filter Design, CRC Press, New York, NY, USA, 1999.

[2] F. Khateb, S. B. Abo Dabbous, and S. Vlassis, "A survey of nonconventional techniques for low-voltage low-power analog circuit design," Radioengineering, vol. 22, no. 2, pp. 415-427, 2013. 
[3] F. Khateb, "Bulk-driven floating-gate and bulk-driven quasifloating-gate techniques for low-voltage low-power analog circuits design," AEU Electronics and Communications Journal, vol. 68, no. 1, pp. 64-72, 2014.

[4] G. Raikos, S. Vlassis, and C. Psychalinos, "0.5 v bulk-driven analog building blocks," International Journal of Electronics and Communications, vol. 66, no. 11, pp. 920-927, 2012.

[5] J. Peyton and V. Walsh, Analog Electronics with Op Amps: A Source Book of Practical Circuits, Cambridge University Press, New York, NY, USA, 1993.

[6] R. G. Irvine, Operational Amplifier Characteristics and Applications, Prentice Hall International, Englewood Cliffs, NJ, USA, 1994.

[7] Z. Wang, "Full-wave precision rectification that is performed in current domain and very suitable for CMOS implementation," IEEE Transactions on Circuits and Systems I, vol. 39, no. 6, pp. 456-462, 1992.

[8] S. J. G. Gift, "A high-performance full-wave rectifier circuit," International Journal of Electronics, vol. 87, no. 8, pp. 925-930, 2000.

[9] P. R. Gray and R. G. Meyer, Analysis and Design of Analog Integrated Circuits, Wiley, New York, NY, USA, 1984.

[10] K. Yamamoto, S. Fujii, and K. Matsuoka, "A single chip FSK modem," IEEE Journal of Solid-State Circuits, vol. 19, no. 6, pp. 855-861, 1984.

[11] C. Toumazou, F. J. Lidgey, and S. Chattong, "High frequency current conveyor precision full-wave rectifier," Electronics Letters, vol. 30, no. 10, pp. 745-746, 1994.

[12] A. A. Khan, M. Abou El-Ela, and M. A. Al-Turaigi, "Currentmode precision rectification," International Journal of Electronics, vol. 79, no. 6, pp. 853-859, 1995.

[13] K. Hayatleh, S. Porta, and F. J. Lidgey, “Temperature independent current conveyor precision rectifier," Electronics Letters, vol. 30, no. 25, pp. 2091-2093, 1995.

[14] W. Surakampontorn, K. Anuntahirunrat, and V. Riewruja, "Sinusoidal frequency doubler and full-wave rectifier using translinear current conveyor," Electronics Letters, vol. 34, no. 22, pp. 2077-2079, 1998.

[15] A. Monpapassorn, K. Dejhan, and F. Cheevasuvit, "CMOS dual output current mode half-wave rectifier," International Journal of Electronics, vol. 88, no. 10, pp. 1073-1084, 2001.

[16] M. Kumngern and K. Dejhan, "Current conveyor-based versatile precision rectifier," WSEAS Transactions on Circuits and Systems, vol. 7, no. 12, pp. 1070-1079, 2008.

[17] E. Yuce, S. Minaei, and O. Cicekoglu, "Full-wave rectifier realization using only two CCII+s and NMOS transistors," International Journal of Electronics, vol. 93, no. 8, pp. 533-541, 2006.

[18] A. Monpapassorn, K. Dejhan, and F. Cheevasuvit, "A full-wave rectifier using a current conveyor and current mirrors," International Journal of Electronics, vol. 88, no. 7, pp. 751-758, 2001.

[19] P. D. Walker and M. M. Green, "CMOS half-wave and fullwave precision voltage rectification circuits," in Proceedings of the 38th IEEE Midwest Symposium on Circuits and Systems, pp. 901-904, Rio de Janeiro, Brazil, August 1995.

[20] V. Riewruja and R. Guntapong, "A low-voltage wide-band CMOS precision full-wave rectifier," International Journal of Electronics, vol. 89, no. 6, pp. 467-476, 2002.

[21] M. Kumngern and K. Dejhan, "High frequency and high precision CMOS full-wave rectifier," International Journal of Electronics, vol. 93, no. 3, pp. 185-199, 2006.
[22] M. Kumngern, P. Saengthong, and S. Junnapiya, "DDCCbased full-wave rectifier," in Proceeding of the 5th International Colloquium on Signal Processing and Its Applications (CSPA '09), pp. 312-315, Kuala Lumpur, Malaysia, March 2009.

[23] M. Kumngern, B. Knobnob, and K. Dejhan, "High frequency and high precision CMOS half-wave rectifier," Circuits, Systems, and Signal Processing, vol. 29, no. 5, pp. 815-836, 2010.

[24] M. Kumngern, "CMOS precision full-wave rectifier using current conveyor," in Proceeding of the IEEE International Conference of Electron Devices and Solid-State Circuits (EDSSC '10), Hong Kong, December 2010.

[25] A. Virattiya, B. Knobnob, and M. Kumngern, "CMOS precision full-wave and half-wave rectifier," in Proceedings of the IEEE International Conference on Computer Science and Automation Engineering (CSAE '11), vol. 4, pp. 556-559, Shanghai, China, June 2011.

[26] H. Mitwong and V. Kasemsuwan, "A $0.5 \mathrm{~V}$ quasi-floating gate self-cascode DTMOS current-mode precision full-wave rectifier," in Proceedings of the 9th International Conference on Electrical Engineering/Electronics, Computer, Telecommunications and Information Technology (ECTI-CON '12), pp. 1-4, May 2012.

[27] M. Kumngern, "Precision full-wave rectifier using two DDCCs," Circuits and Systems, vol. 2, pp. 127-132, 2011.

[28] Wafer Electrical Test Data and SPICE Model Parameters, http:// www.mosis.com/pages/Technical/Testdata/tsmc-018-prm.

[29] F. Khateb, J. Vávra, and D. Biolek, "A novel current-mode fullwave rectifier based on one CDTA and two diodes," Radioengineering, vol. 19, no. 3, pp. 437-445, 2010.

[30] S. M. Zhak, M. W. Baker, and R. Sarpeshkar, "A low-power wide dynamic range envelope detector," IEEE Journal of Solid-State Circuits, vol. 38, no. 10, pp. 1750-1753, 2003.

[31] B. Rumberg and D. W. Graham, "A low-power magnitude detector for analysis of transient-rich signals," IEEE Journal of Solid-State Circuits, vol. 47, no. 3, pp. 676-685, 2012.

[32] E. Rodriguez-Villegas, P. Corbishley, C. Lujan-Martinez, and T. Sanchez-Rodriguez, "An ultra-low-power precision rectifier for biomedical sensors interfacing," Sensors and Actuators, A: Physical, vol. 153, no. 2, pp. 222-229, 2009.

[33] S. Koziel and S. Szczepanski, "Design of highly linear tunable CMOS OTA for continuous-time filters," IEEE Transactions on Circuits and Systems II: Analog and Digital Signal Processing, vol. 49, no. 2, pp. 110-122, 2002.

[34] D. Majumdar, "Comparative study of low voltage OTA designs," in Proceedings of the 17th International Conference on VLSI Design, Concurrently with the 3rd International Conference on Embedded Systems Design, pp. 47-51, January 2004.

[35] R. Li and R. Raut, "A very wideband OTA-C filter in CMOS VLSI technology," in Proceedings of the 7th World Multiconference on Systemics, Cyberetics and Informatics, pp. 1-6, 2003.

[36] L. Zhang, X. Zhang, and E. El-Masry, "A highly linear bulkdriven CMOS OTA for continuous-time filters," Analog Integrated Circuits and Signal Processing, vol. 54, no. 3, pp. 229-236, 2008. 

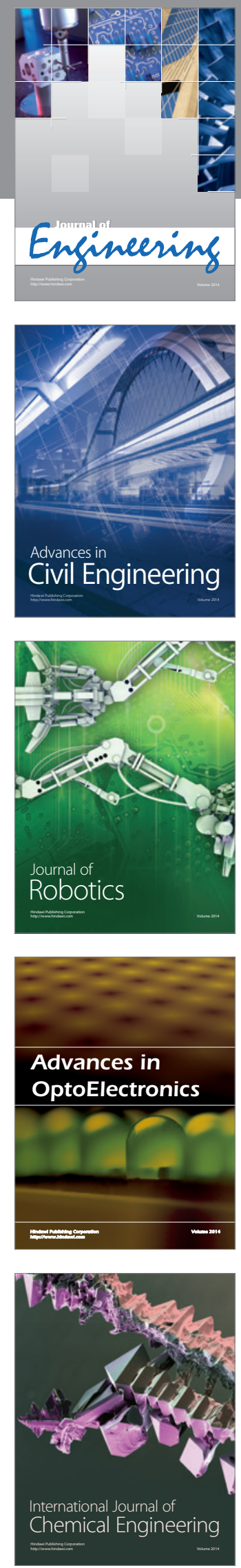

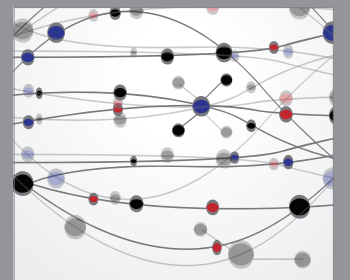

The Scientific World Journal
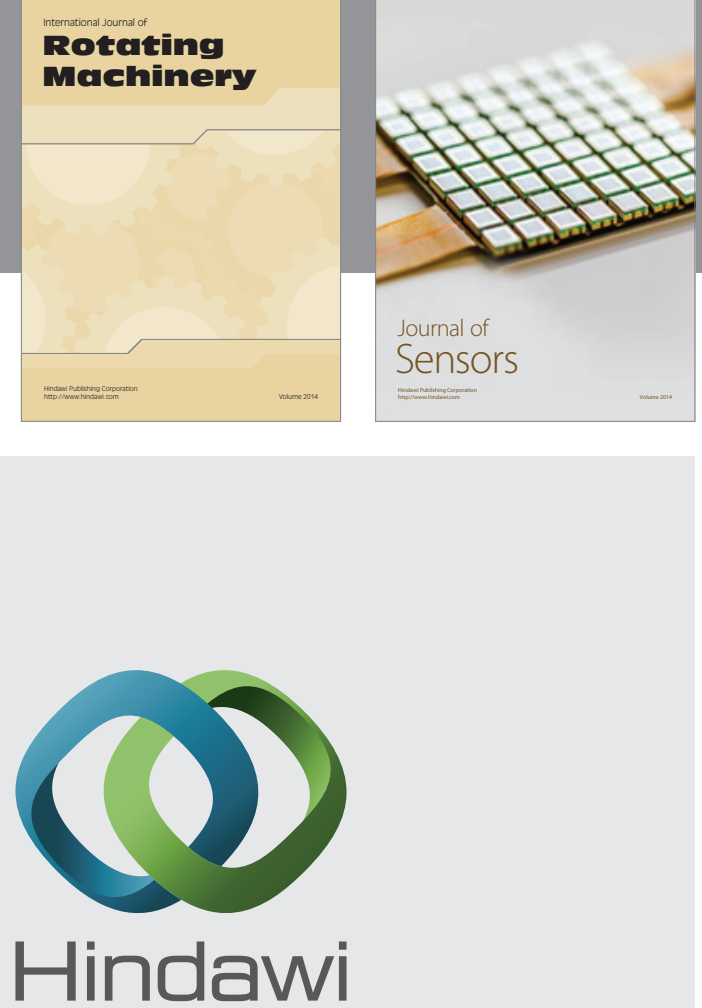

Submit your manuscripts at http://www.hindawi.com
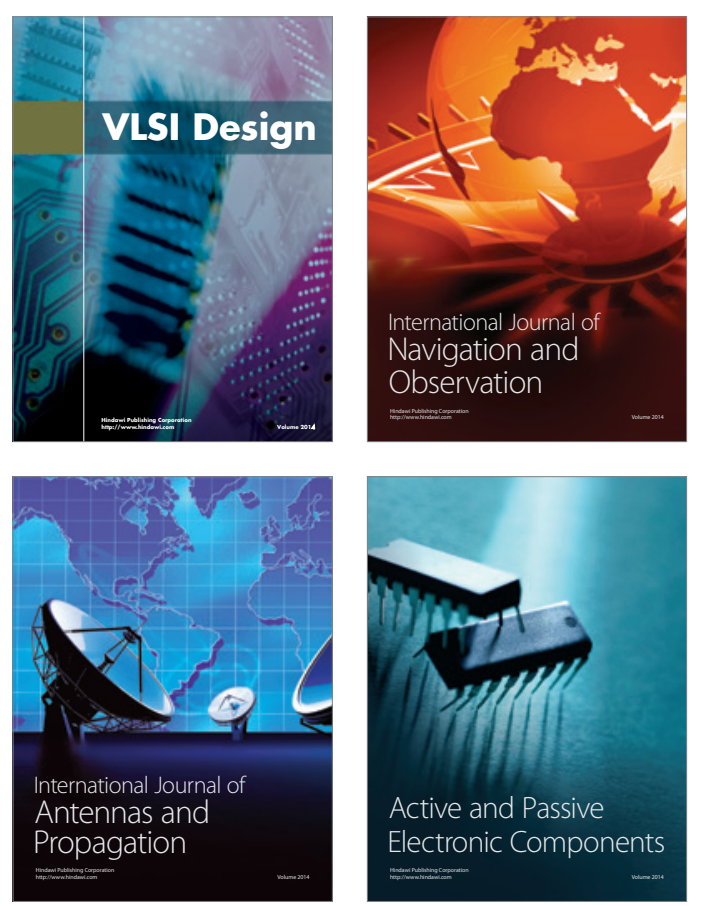
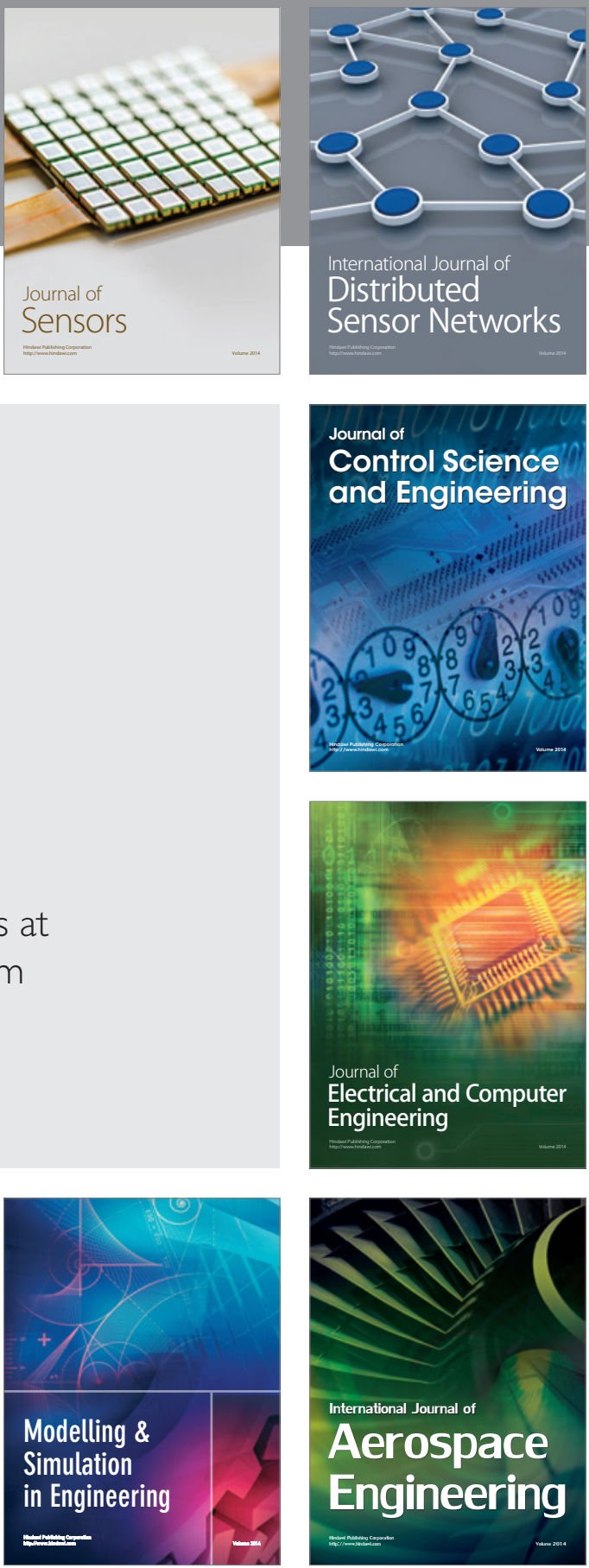

Journal of

Control Science

and Engineering
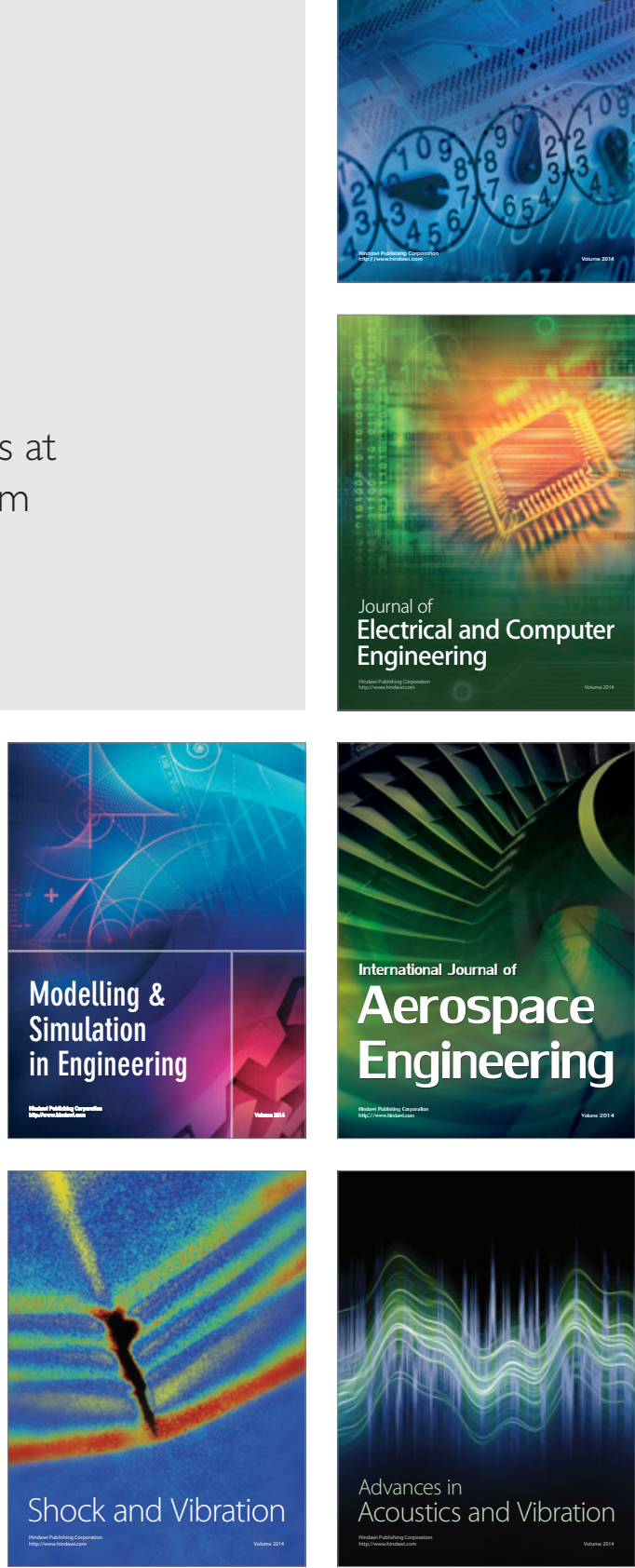